\title{
Holistic sustainability: local culture and global business—a unique opportunity
}

\author{
M. B. Neace \\ Mercer University, USA
}

\begin{abstract}
This paper discusses the role of global enterprises and local culture as primary inputs to attain long-term sustainable development. Several models are discussed showing that today's linear business systems are overly anthropocentric, disconnective, and monolithic in their approach to sustainable development. A business philosophy inclusive of local socio-culture stakeholders respecting their diversity and creativeness as vital constituents to the attainment of sustainable development is proposed. The discussion parallels the UN Global Compact. Broadening business planning to include local stakeholders, incorporating the precautionary principle, and knowledge sharing in a holistic manner with local stakeholders can lead to sustainable communities. The models presented demonstrate this holistic business stratagem.
\end{abstract}

\section{Introduction}

Today, the linear economic reductionist modus operandi is one that extracts resources from Earth, converts them into products and services, and returns the residue (wastes) back to the biosphere (Figure 1). Figure 1 also suggests how this linear system can be modified toward a sustainable paradigm for business and local communities by also including the diversity, creativeness, and wisdom of local culture. Until recently, little thought was given to the impact of the linearreductionist processes, particularly from a holistic perspective, on Planet Earth. All sectors of the global society have and are contributing to this ever-increasing problem. There is now substantial evidence that Planet Earth is not capable of sustaining the continued pace of technological-economic activity it has experienced over the past five decades, and we are losing the battle [30].

This paper offers a holistic schema with several models that address the environmental issue from a business perspective. I contend that adoption of a 
holistic business philosophy has the potential to move the global economy toward a sustainable future using guidelines of the UN Global Compact. I critique the linear reductionist models that most business organizations utilize. Then I discuss a series of models with emphasis on the holistic, interconnectedness character of the biosphere (including Planet Earth and the cosmos) of which local socio-cultural stakeholders are significant contributors to attain holistic sustainable development as integral elements of business strategy.

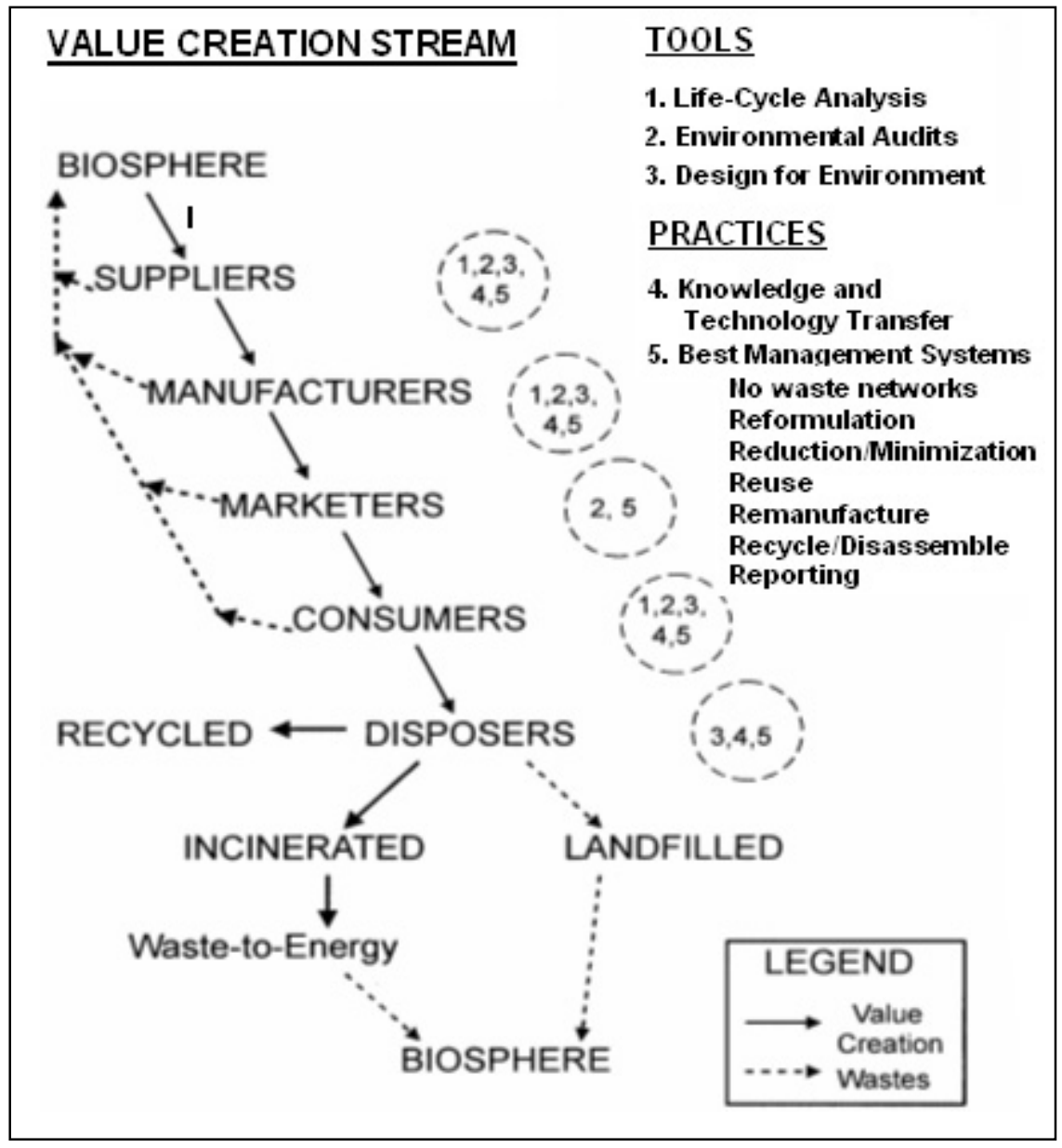

Figure 1: Linear reductionist system converted to an industrial ecology network.

\section{A very brief history of man's view of the world}

The linear-reductionist models that most of the economic-scientific world employs can trace their origins to the civilizations that flourished around the 
Mediterranean basin from 500 B.C. up to the fall of the Roman EmpireHellenism, Judaism, and Christianity. Support and development of this linearreductionist model continued anew after Europe emerged from the Middle Ages. The Renaissance $\left(14^{\text {th }}-17^{\text {th }}\right.$ centuries) followed by the Enlightenment $\left(18^{\text {th }}\right.$ century) were periods of rich human development. Scientists, philosophers, and economists (e.g., Bacon, Locke, Descartes, Newton) flowered during this period, providing underpinnings for the industrial revolution of Europe [29]. Adam Smith showed clearly that production could be increased through specialization - a reductionist approach to manual labor. (See Figure 1 for an overview reductionist model with suggested modifications for sustainability.)

In reductionist models, man views the natural environment as a free resource to be exploited and used for his well-being. Man's control over the natural environment has risen to the level that the natural order of evolutionary processes is ever closer to being anthropogenic rather than biocentric. Continued application of linear models on par with the accelerated pace of the past five decades is unsustainable [3,28] (Figure 2).

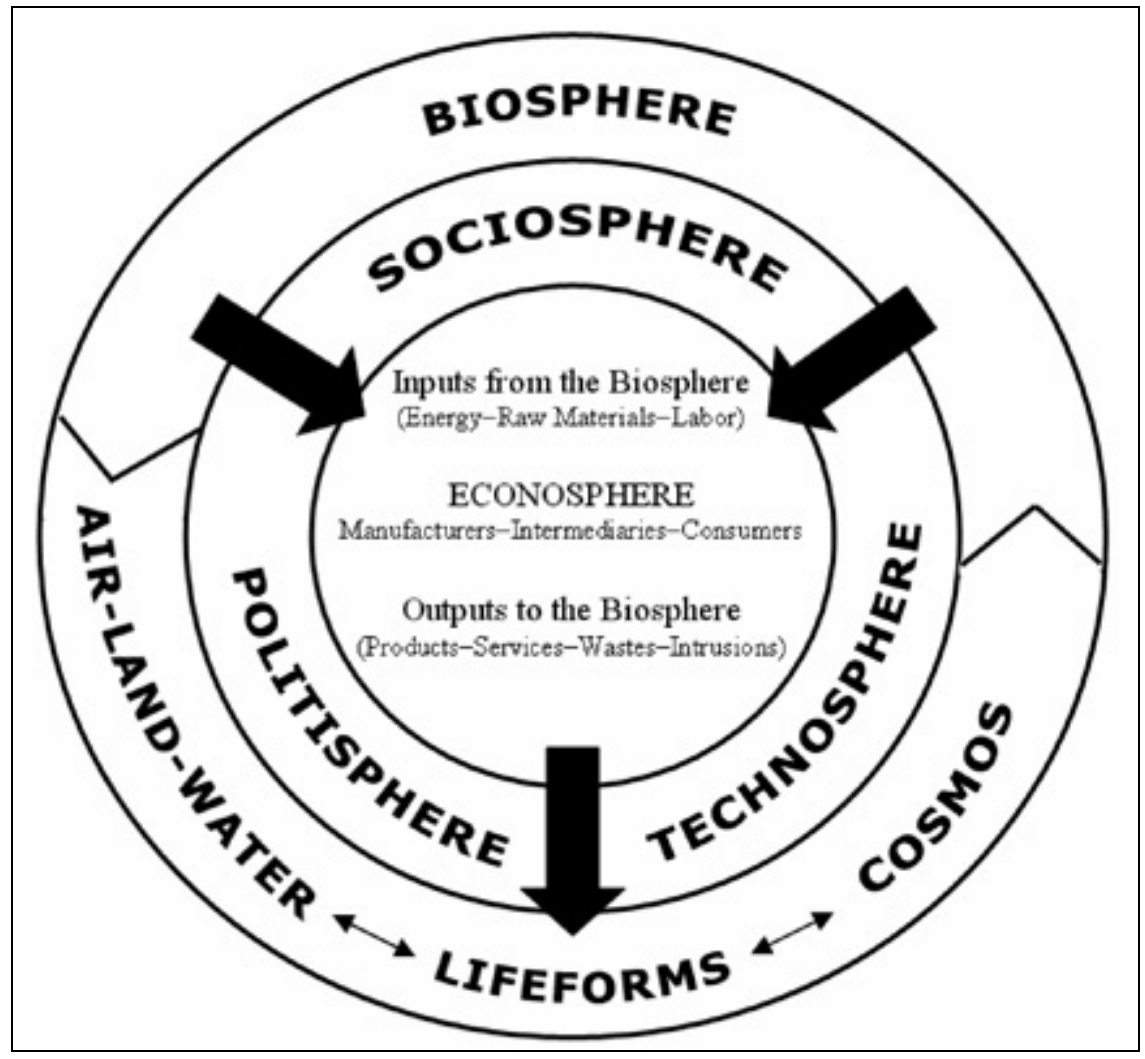

Figure 2: $\quad$ The human-biosphere interface. 


\section{Critique of the anthropocentric linear model}

Development of the linear model has not gone unchallenged. Recently, a number of writers have raised serious questions about the limitations surrounding the application of classical Western scientific/economic traditions $[6,8,9,12,15,22,24,25]$, but probably none more significant or impressive than Rachel Carson's Silent spring [5]. Her writings introduced ecology and its concept of interconnectedness of living things in nature to the public and spurred a heated debate and a spate of legislative activity in the Western World to protect the natural environment.

There are several reasons why reversing the rate of biospheric degradation has been elusive: (1) few national governments have had the political will to enforce environmental laws or make the necessary changes in their economic/social policies and structures; (2) the disconnectedness of production and consumption from the underpinning biospheric base; and (3) the lack of awareness and knowledge of the dynamic relationships between humans and Planet Earth [2,22]. What is lacking is a paradigm, both theoretical and operational, that reunites man to his biosphere [21].

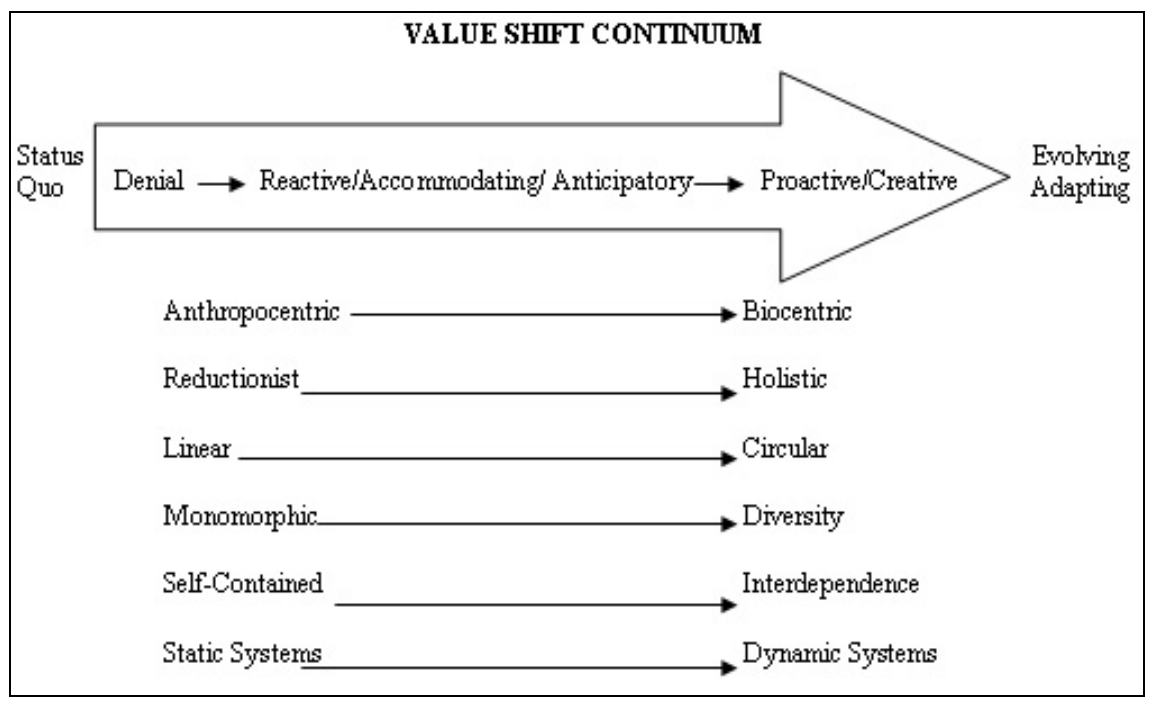

Figure 3: $\quad$ Transformation of values.

\section{The transformation process}

Response to environmental crises over the past three decades has evolved through a transformation process consisting of several stages: Beginning with denial of environmental problems and refuting the "questionable" scientific data base in the late $60 \mathrm{~s}$, to transforming values to reactive/anticipatory, and, now, to proactive/creative endeavours [21] (Figure 3). Sustainable development bridges 
the gap between ecology and economics. Today, there is increasing support in the global business community for the UN Global Compact to close this gap (www.unglobalcompact.org).

Figure 3 illustrates the value transformation necessary to reach new levels of maturity, understanding, and potential for progress for all participants. Most writers on this subject agree that as transformation takes place and as business learns more about the workings of Planet Earth and its biosphere, its technologies and practices will be less damaging to the environment [18].

For the business community, this means de-compartmentalizing functions, practices, and supply chains and listening to fellow stakeholders outside the establishment [1]. Norgaard [23] describes these relationships as linkages, not a synthesis of unlike paradigms, but symbioses, whereby each unit is enriched because of its differences. No business is being asked to forego its efforts at satisfying consumers, shareholders, and other stakeholders. It will take a staggering amount of good business practices and cooperation to move in the direction of sustainable development - a holistic schema. That can only be attained by use of an inclusionary philosophy-all relevant stakeholders. Figure 4 expresses this integrated holistic concept.

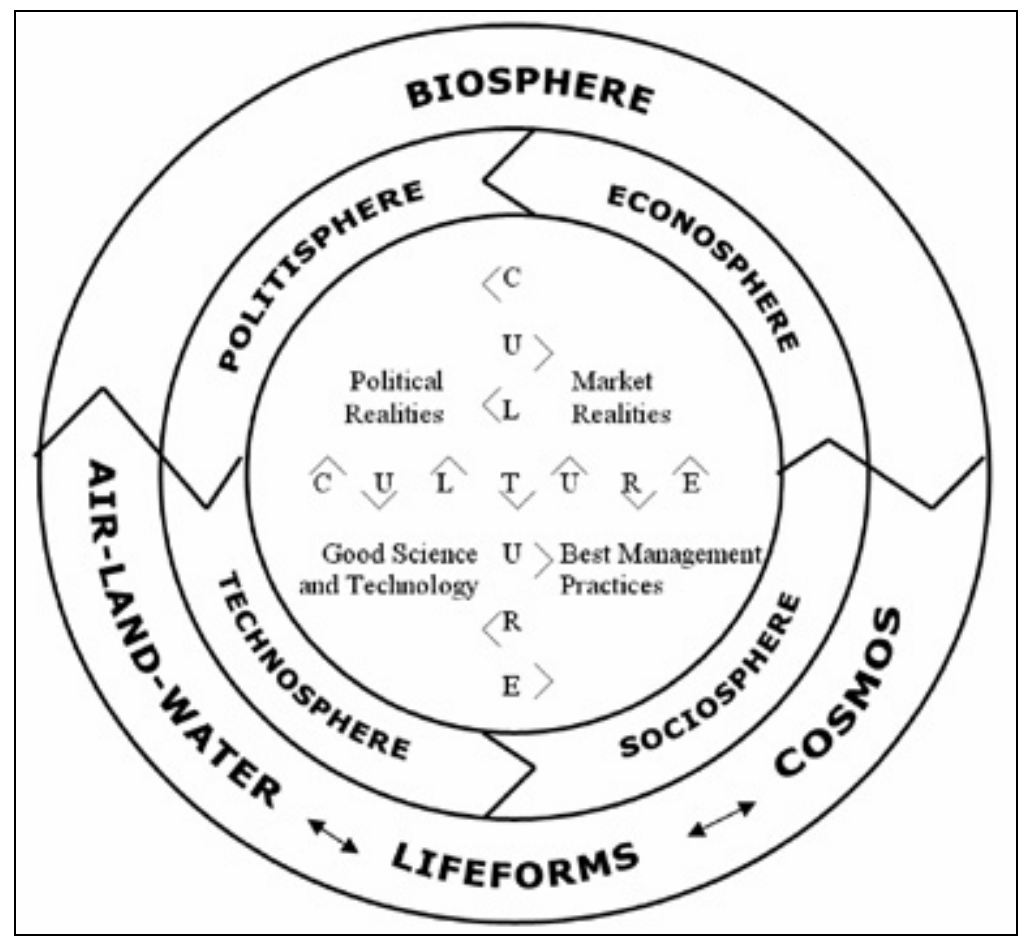

Figure 4: Integrated holistic paradigm. 
Value shifting to the proactive/creative level leads naturally to synergistic activities, blending economics and ecology through combinations of good science, best management practices, and the inclusion of local stakeholders [30-32]. The global business community plays a key role in this process: they have the knowledge, they have the skills, they understand risk (the precautionary principle), and they have the ability to create win-win-win situations - a triple bottom line. Other stakeholders at the local level play pivotal roles in the development and application of sustainable initiatives, including research, education, and formulation of regulatory policies and transforming these preparations into good science and best management practices.

Building on Norgaard's [23] plea for pluralism, it is essential for the global business community to recognize and respect that different groups and cultures have unique approaches to their view of the world, applying different assumptions and methodologies that result in different models of the "same" phenomena. It is this very diversity and the synergy it creates that holds promise for progress toward a planetary system of sustainable development.

Those of us in the scholarly-intellectual world, because of our professional ethos, should foster creative opportunities for cross-functional, crossorganizational programs (teaching, research, management, policy formulation) within and among our institutions and with other stakeholders. Only in this way can we truly develop the holistic, interconnected, dynamic paradigms necessary for movement toward sustainable development [36].

\section{Making sustainability operational}

Limitations of present environmental policies and programs are well known, including bureaucratic ineptness and lack of will [14], short-term economicpolitical "remedies" at the sacrifice of long-term biosphere reality $[13,27,32]$, and application of reductionist paradigms when increasing evidence points to a holistic dynamic general system [4,9,16,20,29,33-35]. Overcoming these issues is what the UN Global Compact is all about.

A holistic perspective is required. Norgaard [23], Rothschild [29], and Teilhard [35], among others, have developed holistic models that largely focus on "horizontal" dynamics and the integration of global enterprises, national economies, and political policies. These efforts have led to significant progress in our understanding of Earth. Also needed is a vertical dynamic that encourages discussion of concepts, policies, and supply chains throughout all levels of the global community - dynamic networking.

Twenty-five years of "command and control" policies targeted at the most obvious and egregious environmental problems are complex and, now, only marginally productive [22]. Continued progress in alleviating biospheric problems due to man's intrusions and consumption is proving to be difficult, and assuring a sustainable future requires global business leadership. Holistic and inter-vertical new initiatives, such as the UN Global Compact, are "forcing" the creative strategic plans of global enterprises to the local level; e.g., community pollution prevention programs, local government partnering, and business compliance assistance. 
Many observers of the present environmental dilemma believe a significant number of undesirable outcomes of a monomorphic, elitist bureaucracy could have been avoided with local socio-cultural input and gradual withdrawal of central control $[10,11,14,19,26]$. No one is suggesting that government abandon its responsibility of serving its peoples. But a growing number of business leaders, professionals, and scholars are suggesting a gradual withdrawal of central control. In most well-educated communities with rising levels of human consciousness and awareness of the connectedness of all life forms [35], central control just doesn't work; for example, the collapse of the Russian empire. Randhir and Lee [26] see the role of central government as an external observer, supplier of technical know-how, nurturer of mutual trust among the variety of stakeholders, and assistant to the development of well-structured incentive systems.

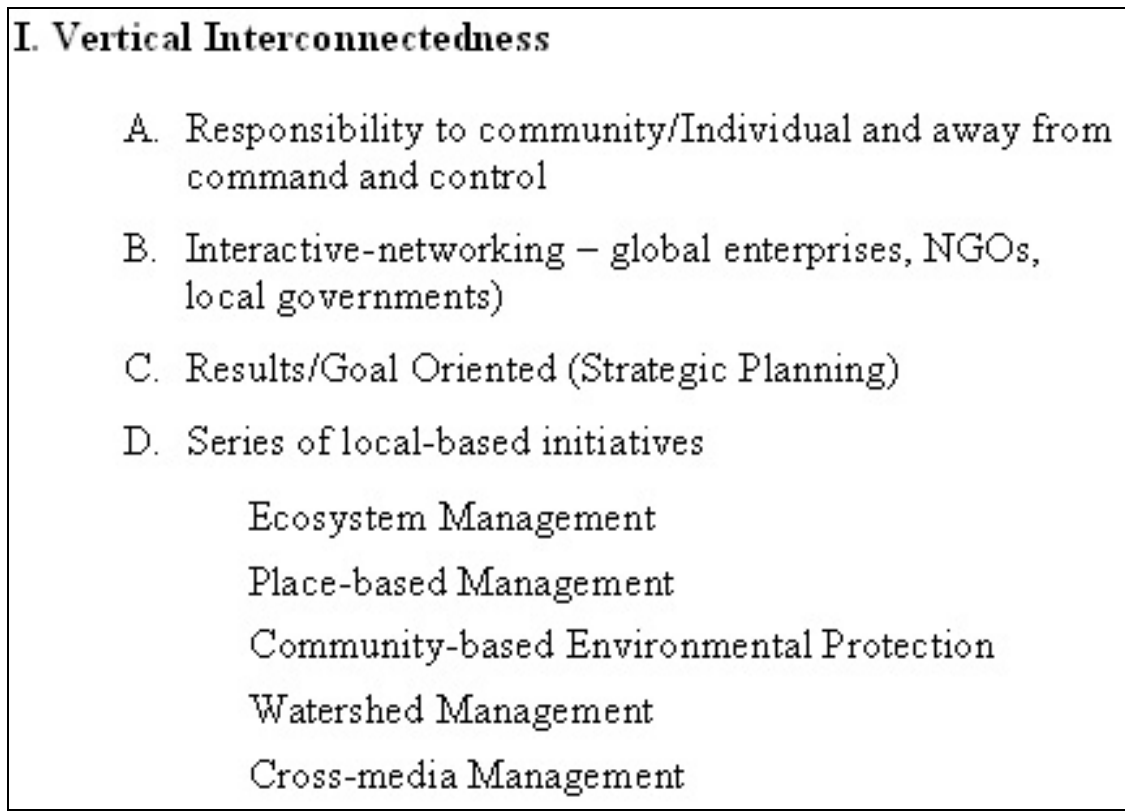

Figure 5: $\quad$ Making sustainability operational-missing links.

\section{Conclusion}

To approach a life-style that is sustainable, the global business community will have to expand its linear-reductionist orientation to encompass a holistic view of man, Earth, and the cosmos, similar to the view of the UN Global Compact. Are the global enterprises of the world ready to utilize these resources in their economic and strategic planning? Are global enterprises ready to embrace fellow local stakeholders as integral parts? 
Several respected scientific journalists claim that the hard data says the battle is being lost $[7,17]$. For sustainability to move toward becoming a reality, global enterprises, global NGOs, and local socio-culture communities should implement general systems as a matter of general course. The global business community has the opportunity as well as the responsibility of encouraging this inclusiveness for the betterment of all, for creating triple bottom lines.

\section{Local Socio-Cultural Participation}
A. Sustainability requires input of local stakeholders
B. Power/Incentives to local stakeholders
1. Farmers/Ranchers
2. Small manufacturers
3. Community leaders
4. Consumers
5. NGOs
C. Gradual withdrawal of central government
D. Freedom, Diversity, Tolerance
E. Risk/Strength/Creativity
F. More decision makers
G. Successful ideas increase
H. Self-interest/Creativity

Figure 6: Making sustainability operational—missing links.

\section{References}

[1] Benson, William H. (1995). "Better science makes for better decisions," Environmental toxicology and chemistry, (Vol. 14, No. 11), 1811-1812.

[2] Berry, Thomas (1988). The dream of the earth. San Francisco: Sierra Club Books.

[3] Boulding, Kenneth E. (1966). "The economics of the coming spaceship earth," in Environmental quality in a growing economy, Henry Jarrett, ed. Baltimore: Johns Hopkins Press, 3-14.

[4] Burrows, Brian C., Alan J. Mayne, and Paul Newberry (1991). Into the $21^{\text {st }}$ Century. Twickenham, U.K.: Adamantine Press Limited.

[5] Carson, Rachael (1962). Silent spring. Boston: Houghton-Mifflin. 
[6] Clark, Mary E. (1989). Ariadne's thread. New York: St. Martins Press.

[7] Connor, Steve (2005). "The final proof: Global warming is a man-made disaster," The independent.

[8] Costanza, Robert (1991). Ecological economics: The science and management of sustainable development. New York: Columbia University Press.

[9] Daly, Herman E. (1991). Steady-state economics, $2^{\text {nd }}$ ed. Washington D.C.: Island Press.

[10] DeGraaf, H. J., C. J. M. Musters and W. J. TerKeurs (1996). "Sustainable development: Looking for new strategies," Ecological economics, (Vol. 16, No. 3), 205-216.

[11] Enama, Mugangu T. (1994). "Culture: The missing nexus in ecological economics perspectives," Ecological economics, (Vol. X, No. 2), 93-95.

[12] Hardin, Garrett (1968). "The tragedy of the commons," Science, (13 December), 1234-1248.

[13] Hawken, Paul (1993). The ecology of commerce. New York: Harper Collins Publishers.

[14] Hess, Karl, Jr. (1992). Visions upon the land. Washington, D.C.: Island Press.

[15] Laborit, Henri (1985). "The Complexity of Interdependence in Living Systems" in The Science and Praxis of Complexity. Tokyo: The United Nations University, 146-169.

[16] Lovelock, James E. (1979). Gaia: A new look at life on earth. New York: Oxford University Press.

[17] McCarthy, Michael (2005). "Needed: A new Manhattan project," The independent.

[18] Nash, Roderick F. (1989). The rights of nature. Madison, WI: University of Wisconsin Press.

[19] Neace, M. B. (2005). "Adding co-evolutionary principles to a holistic paradigm of sustainable development," Ecosystems and sustainable development $V$, eds. E. Tiezze, et al. Southampton, UK: WIT Press, 2005, 355-364.

[20] Neace, M. B. (2003). "The catalytic role of the science community: Aking sustainability work," in Ecosystems and sustainable development, eds. Tiezzi, Brebbia, and Uso. Southampton, UK: WIT Press, 603 - 611.

[21] Neace, M. B. (1998). "Sustainable development: A critique and proposal," in Ecosystems and sustainable development, eds., J. L. Uso, et al. Southampton, UK: WIT Press, 105-113.

[22] Norgaard, Richard B. (1994). Progress betrayed: The end of progress and a coevolutionary revisioning of the future. NY: Routledge.

[23] Norgaard, Richard B. (1985). "Environmental economics: An evolutionary and a pleas for pluralism," Journal of environmental economics and management, (December), 382-394.

[24] Odum, Howard T. (1971). Environment, power and society. New York: John Wiley and Sons.

[25] Prigogine, Llya (1985). "New perspectives on complexity," in The science 
and praxis of complexity. Tokyo: The United Nations University, 107118.

[26] Randhir, Timothy O. and John G. Lee (1996). "Managing local commons in developing economics: An institutional approach," Ecological economics, (Vol. 16, No. 1), 1-12.

[27] Rees, William (1990). Sustainable development and the biosphere. Chambersburg, PA: ANIMA Books.

[28] Repetto, Robert (ed.) (1985). The global possible. Washington, D. C.: World Resources Institute.

[29] Rothschild, Michael (1990). Bionomics. New York: Henry Holt and Company.

[30] Royston, Michael G. (1979). Pollution prevention pays. New York: Pergamon Press.

[31] Saunders, Tedd and Loretta McGovern (1994). The bottom line of green is black: Strategies for creating profitable and environmentally sound business. San Francisco: Harper.

[32] Schmidheiny, Stephan (1992). Changing course: A global business perspective on development and the environment. Cambridge, MA: MIT Press.

[33] Stikker, Allerd (1992). The transformation factor. Rockport, MA: Element, Inc.

[34] Tarnas, Richard (1991). The passion of the western mind. New York: Harmon Books.

[35] Teilhard de Chardin, Pierre (1959). The phenomenon of man. New York: Harper.

[36] Vedeld, Paul O. (1994). "The environment and interdisciplinary ecological and neoclassical economical approaches to the use of natural resources," Ecological economics, (Vol. 10, No.1), 1-13. 